\section{Phrase Length}

Julie Griffith

Department of Speech Pathology and Audiology, Ball State University, Muncie, IN, USA

\section{Synonyms}

Breath group; Intonation phrase; Prosodic phrase

\section{Definition}

One or more words that convey a single idea and may or may not adhere to grammatical conventions to form a complete phrase or sentence. "Phrase length" is demarcated in connected speech at the end of a clear pitch contour and/or at the period of silence during which the speaker pauses for a breath.

Phrase length has been used to classify types of aphasia into fluent or nonfluent (Goodglass et al. 2001). People with fluent aphasia produce phrase lengths with at least five to six words, while people with nonfluent aphasia produce three to four word phrases.

\section{Cross-References}

- Aphasia

- Boston Diagnostic Aphasia Examination

- Discourse Assessment

- Prosody

\section{References and Readings}

Goodglass, H., Quadfasel, F. A., \& Timberlake, W. H. (1964). Phrase length and the type and severity of aphasia. Cortex, 1, 139-143.

Goodglass, H., Kaplan, E., \& Barresi, B. (2001). The assessment of aphasia and related disorders (3rd ed.). Philadelphia: Lippincott Williams \& Wilkins.

Reed, B. S. (2009). Units of interaction: 'Intonation phrases' or 'turn constructional phrases'? Proceedings of ICD, 9, 351-363. 